\title{
BIOACUMULAÇÃO DE METAIS PESADOS E NUTRIENTES NO MEXILHÃO DOURADO DO RESERVATÓRIO DA USINA HIDRELÉTRICA DE ITAIPU BINACIONAL
}

\author{
Nilton Garcia Marengoni*, Elcio Silvério Klosowski, Katiane Pimenta de Oliveira, Ana Paula Sartorio Chambo e Affonso \\ Celso Gonçalves Junior \\ Universidade Estadual do Oeste do Paraná, Campus de Mal. Cândido Rondon, Rua Pernambuco, 1777, 85960-000 Marechal \\ Cândido Rondon - PR, Brasil
}

Recebido em 18/2/12; aceito em 25/9/12; publicado na web em 23/1/13

\begin{abstract}
BIOACCUMULATION OF HEAVY METALS AND NUTRIENTS IN THE GOLDEN MUSSEL OF THE RESERVOIR OF THE ITAIPU BINATIONAL HYDROELECTRIC POWER PLANT. This study aims to evaluate the bioaccumulation of macronutrients and heavy metals in the golden mussel according to its collection site and seasonality in the aquaculture area of the reservoir from April/2009 to March/2010. There is no difference $(p>0.05)$ in the concentration of metals with respect to the point of collection. The concentrations of $\mathrm{Cu}, \mathrm{Fe}, \mathrm{Mn}, \mathrm{Zn}, \mathrm{Cd}$ and $\mathrm{Pb}$ were higher $(\mathrm{p}<0.05)$ in spring and summer than in fall and winter. Values of the heavy-metal pollution index (MPI) for collection point and seasonality indicate environmental contamination in the aquaculture area.
\end{abstract}

Keywords: trace element; Limnoperna fortunei; pollution index.

\section{INTRODUÇÃO}

O monitoramento da concentração de metais em ambientes aquáticos por meio de organismos vivos tem sido objeto de estudo nos últimos anos. Devido ao crescimento da população mundial, a rápida industrialização, a intensificação da aquicultura e a utilização indiscriminada dos recursos naturais têm gerado aumento nos níveis de poluição ambiental, causando sérios problemas para o ecossistema, principalmente devido à contaminação química.

Os moluscos bivalves estão amplamente difundidos e são abundantes em ecossistemas aquáticos, apresentam alta tolerância a vários poluentes, podendo bioacumular e translocar, por meio da cadeia trófica, compostos antropogênicos originados de várias fontes. ${ }^{1}$ Estes invertebrados respondem sensivelmente aos estímulos ambientais e, por isto, são amplamente utilizados como organismos indicadores de variações no ambiente aquático, pois podem refletir os níveis de contaminantes presentes in loco. ${ }^{2}$

O Limnoperna fortunei ou mexilhão dourado é um molusco bivalve autóctone de rios e arroios do sudeste da Ásia e passou a ser observado na América do Sul a partir da década de 90, pela introdução não intencional. ${ }^{3,4}$

Os primeiros registros deste organismo no Brasil ocorreram em 1998 no Pantanal Matogrossense, incrustado nas embarcações. ${ }^{5}$ No estado do Paraná sua presença foi relatada em meados de 2002, no Lago de Itaipu no Rio Paraná e, posteriormente, nas usinas hidrelétricas de Ilha Solteira, Jupiá e Porto Primavera. Este molusco invasor se reproduz demasiadamente e em densidades elevadas causa grandes danos econômicos, formando aglomerações que dominam o ambiente invadido, gerando problemas nos sistemas de captação de água, nos sistemas de resfriamento de usina hidrelétrica, motores de embarcações e tubulações. ${ }^{3-6}$

$\mathrm{O}$ Limnoperna fortunei pertence à família Mytilidae e assemelha-se ao mexilhão marinho. São organismos bentônicos filtradores que se alimentam de partículas suspensas na água, principalmente fitoplâncton, podendo alterar substancialmente a dinâmica trófica do ecossistema aquático, reduzindo a biomassa vegetal e a quantidade de sólidos suspensos, podendo contribuir para o aumento da transparência da água. ${ }^{7,8}$

*e-mail: nmarengoni@hotmail.com
Os moluscos são capazes de remover substâncias tóxicas como metais pesados, agrotóxicos e toxinas presentes na água e bioacumular em seus tecidos e de outros organismos aquáticos, causando deterioração letal ou subletal. Os metais tóxicos $(\mathrm{Pb}, \mathrm{Cd}$ e $\mathrm{Cr})$ e metais pesados biologicamente essenciais ( $\mathrm{Zn}, \mathrm{Fe}, \mathrm{Cu}$ e $\mathrm{Mn}$ ), quando acumulados em quantidades elevadas, provocam danos aos seres vivos. No ambiente aquático, há um expressivo potencial poluente nos sedimentos, nas plantas e animais, bioacumulando-se ao longo da cadeia trófica, podendo alterar o equilíbrio da biota aquática, por meio da contaminação ambiental e dos distúrbios decorrentes da superexposição. ${ }^{9}$

O presente estudo objetivou avaliar a bioacumulação de metais pesados e nutrientes no mexilhão dourado em relação ao ponto de coleta e sazonalidade, na área aquícola do reservatório da usina hidrelétrica de Itaipu Binacional no município de Santa Helena, Paraná, Brasil, durante o cultivo de peixes autóctones em tanques rede.

\section{PARTE EXPERIMENTAL}

\section{Caracterização do local de estudo}

O estudo foi realizado no reservatório da usina hidrelétrica de Itaipu Binacional, em uma área aquícola destinada ao cultivo experimental de peixes nativos em tanques rede no município de Santa Helena-PR, área do Refúgio Biológico na região Oeste do Estado. A área de estudo faz parte da zona de transição do Rio Paraná, com as coordenadas geográficas W 54 21' 196', S 24 51' 105', W $54^{\circ}$

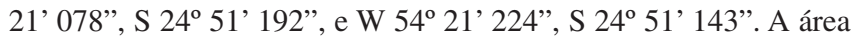
aquícola onde estão instalados os tanques rede encontra-se a uma profundidade média de $8 \mathrm{~m}$, com características normais de vazão do reservatório. A unidade de cultivo possui 6 linhas com 12 tanques de $5 \mathrm{~m}^{3}$, com espaçamento entre linhas de aproximadamente $20 \mathrm{~m} \mathrm{e}$ $2 \mathrm{~m}$ entre os tanques rede.

\section{Coleta e análise das amostras}

Durante o período de abril de 2009 a março de 2010 foram coletadas amostras mensais do mexilhão dourado Limnoperna fortunei (Dunker 1857), em dois pontos, sendo que o Ponto $1\left(\mathrm{P}_{1}\right)$ se 
caracteriza pela incrustação do mexilhão na borda externa do tanque rede, localizado no centro da área aquícola e o Ponto $2\left(\mathrm{P}_{2}\right)$ se refere à boia náutica disposta a $100 \mathrm{~m}$ dos tanques rede, na margem direita da área aquícola.

Os mexilhões foram removidos com a ajuda de uma espátula plástica, previamente lavados com água do reservatório para eliminar resíduos de matéria orgânica e, em seguida, acondicionados em embalagens plásticas identificadas e transportados, em caixas térmicas contendo gelo, até a Universidade Estadual do Oeste do Paraná (Unioeste). As amostras de mexilhões foram separadas, pesadas e padronizadas em média de $600 \mathrm{~g}$ de mexilhões com tamanho médio da concha de $30 \mathrm{~mm}$, caracterizados como adultos. ${ }^{10}$ Após a secagem em estufa de circulação de ar forçada a $55^{\circ} \mathrm{C}$ por $48 \mathrm{~h}$ foram moídas e encaminhadas à análise química no Laboratório de Química Ambiental e Instrumental da Unioeste.

Foram mensuradas as concentrações totais de potássio $(\mathrm{K})$, cálcio (Ca), magnésio $(\mathrm{Mg})$, cobre $(\mathrm{Cu})$, ferro $(\mathrm{Fe})$, manganês $(\mathrm{Mn})$ e zinco $(\mathrm{Zn})$ e dos metais pesados cádmio $(\mathrm{Cd})$, cromo $(\mathrm{Cr})$ e chumbo $(\mathrm{Pb})$ por meio da digestão nitro perclórica ${ }^{11}$ das amostras e quantificação por espectrometria de absorção atômica com chama (FAAS),$^{12}$ utilizando o equipamento da marca GBC, modelo 932AA. A quantificação da concentração de fósforo total $(\mathrm{P})$ foi obtida pelo método ultravioleta visível (UV-Vis). O nitrogênio total $(\mathrm{N})$ foi quantificado por digestão sulfúrica de acordo com o método Kjeldahl. ${ }^{13}$

Utilizaram-se padrões inorgânicos aquosos para a calibração e todas as análises foram determinadas em triplicata. O limite de quantificação para os metais tóxicos foi de $0,01 \mathrm{mg} \mathrm{kg}^{-1}$.

\section{Monitoramento da qualidade da água e precipitação}

Durante as coletas das amostras realizou-se o monitoramento in loco da água nos pontos $\mathrm{P}_{1}$ e $\mathrm{P}_{2}$ demarcados, onde foram obtidas as variáveis de temperatura da água com um termômetro digital. O potencial hidrogeniônico $(\mathrm{pH})$ foi mensurado por meio do potenciômetro de campo modelo pH Master, da Gulton do Brasil Ltda. A transparência da água foi medida pelo disco de Secchi e a condutividade e o oxigênio dissolvido, com aparelhos digitais portáteis da Alfakit ${ }^{\circledR}$, modelos AT-110 e AT-130, respectivamente. Os dados de precipitação mensal na área aquícola do reservatório da usina hidrelétrica de Itaipu Binacional foram fornecidos pelo Instituto Tecnológico Simepar/ Santa Helena-PR.

\section{Índice de poluição por metal (MPI)}

O índice de poluição por metais (MPI) foi determinado para os micronutrientes $(\mathrm{Cu}, \mathrm{Fe}, \mathrm{Mn}, \mathrm{Zn}, \mathrm{Cd}, \mathrm{Pb}$ e $\mathrm{Cr})$ e metais tóxicos $(\mathrm{Cd}$, $\mathrm{Pb}$ e $\mathrm{Cr}$ ), utilizando-se a equação $\mathrm{MPI}=\left(\mathrm{CF}_{1} \times \mathrm{CF}_{2} \times \mathrm{CF}_{3} \ldots \ldots \mathrm{CF}_{\mathrm{n}}\right)^{1 / \mathrm{n}}$, onde, $\mathrm{CF}_{\mathrm{n}}=$ concentração de metal na amostra $n .{ }^{14}$

\section{Análise estatística}

Os valores médios dos metais quantificados nas amostras nos 2 pontos de coleta e nas 4 estações, durante o período de coleta, foram submetidos à análise de variância (ANOVA), seguidas de teste de Tukey por meio do Software SAS. . $^{15}$

\section{RESULTADOS E DISCUSSÃO}

A água da área de estudo destaca-se, de acordo com os limites estabelecidos na Resolução $n^{\circ} .357$ do Conselho Nacional do Meio Ambiente (CONAMA), ${ }^{16}$ como água doce classe 1 , podendo ser considerada como área oligotrófica ${ }^{17}$ e apropriada para aquicultura em tanques rede (Tabela 1). Os parâmetros físicos e químicos da água não apresentaram variação sazonal $(p>0,05)$, possivelmente devido à dinâmica do reservatório da usina hidrelétrica de Itaipu.

Verifica-se na Tabela 2 que não houve diferença $(\mathrm{p}>0,05)$ para os valores médios de N, P, K, Mg e Ca nas amostras de Limnoperna fortunei em relação ao ponto de coleta. As concentrações máximas de N, P, K, Mg e Ca verificadas em $\mathrm{P}_{1}$ e $\mathrm{P}_{2}$ foram de 32,38 e 35,00 $\mathrm{g} \mathrm{kg}^{-1} ; 2,17$ e $2,02 \mathrm{~g} \mathrm{~kg}^{-1} ; 2,70$ e $1,05 \mathrm{~g} \mathrm{~kg}^{-1} ; 13,65$ e $12,25 \mathrm{~g} \mathrm{~kg}^{-1}$; 148,75 e $141,05 \mathrm{~g} \mathrm{~kg}^{-1}$, respectivamente.

Estudando os macronutrientes nas conchas de ostras e mexilhões em 3 locais de coleta, Silva ${ }^{18}$ destacou o cálcio como o elemento de maior percentual em função da estrutura de constituição da concha ser predominantemente de carbonato de cálcio. As quantidades de $\mathrm{Ca}, \mathrm{N}$ e K apresentam-se superiores no mexilhão dourado quando comparado às conchas de ostras e mexilhões marinhos. Corroborando este trabalho, Agripino ${ }^{19}$ ao estudar duas espécies de ostras, Crassostrea angulata e Crassostrea gigas, encontrou valores médios inferiores aos determinados neste trabalho para as concentrações de N, P, Ca e $\mathrm{Mg}$, sendo avaliados os mexilhões inteiros (Tabela 2), diferindo dos estudos anteriores que foram apenas com a concha.

Os valores médios dos micronutrientes $\mathrm{Cu}, \mathrm{Fe}, \mathrm{Mn}$ e $\mathrm{Zn}$ e dos metais tóxicos $\mathrm{Pb}, \mathrm{Cd}$ e $\mathrm{Cr}$, nas amostras de Limnoperna fortunei não apresentaram diferença $(\mathrm{p}>0,05)$ quanto aos pontos de coleta na área aquícola (Tabela 3).

As concentrações máximas de $\mathrm{Cu}\left(27\right.$ e $\left.30 \mathrm{mg} \mathrm{kg}^{-1}\right)$ e $\mathrm{Zn}(48$ e 45 $\left.\mathrm{mg} \mathrm{kg}^{-1}\right)$, respectivamente, para as amostras de mexilhão no $\mathrm{P}_{1}$ e $\mathrm{P}_{2}$ estão dentro dos limites preconizados pela legislação, ${ }^{20}$ que embora destinada a alimentos, os valores máximos permitidos para $\mathrm{Cu}$ e $\mathrm{Zn}$ são, respectivamente, 30,00 e $50,00 \mathrm{mg} \mathrm{kg}^{-1}$ (Tabela 3). Os níveis encontrados para os micronutrientes não indicam existir contaminação ambiental por estes metais. A legislação brasileira em vigor não delimita níveis máximos permitidos para concentração de manganês e ferro em alimentos.

Diferindo dos resultados apresentados na Tabela 3, outros pesquisadores $^{21}$ encontraram concentração de $\mathrm{Cu}(199,09$ mg kg-1)

Tabela 1. Sazonalidade e desvio padrão (sd) das variáveis físicas e químicas da água na área aquícola (in loco) em dois pontos $\left(\mathrm{P}_{1}=\right.$ tanque rede e $\mathrm{P}_{2}=$ boia localizada a $100 \mathrm{~m}$ do tanque rede), durante o período de abril de 2009 a março de 2010. (n = 3)

\begin{tabular}{|c|c|c|c|c|c|c|}
\hline Estação & Ponto & $\mathrm{pH}$ & $\begin{array}{l}\text { Temperatura } \\
\left({ }^{\circ} \mathrm{C}\right)\end{array}$ & $\begin{array}{l}\text { Condutividade } \\
\left.(\mu \mathrm{S} \mathrm{cm})^{-1}\right)\end{array}$ & $\begin{array}{l}\text { Transparência } \\
\text { (m) }\end{array}$ & $\begin{array}{c}\mathrm{O}_{2} \mathrm{D} \\
\left(\mathrm{mg} \mathrm{L}^{-1}\right)\end{array}$ \\
\hline \multirow[t]{2}{*}{ Primavera } & $\mathrm{P}_{1}$ & $7,68 \pm 0,24$ & $25,17 \pm 1,26$ & $56,95 \pm 1,66$ & $1,83 \pm 0,50$ & $7,94 \pm 1,05$ \\
\hline & $\mathrm{P}_{2}$ & $8,04 \pm 0,50$ & $25,00 \pm 1,00$ & $57,17 \pm 1,21$ & $2,12 \pm 0,10$ & $7,57 \pm 1,18$ \\
\hline \multirow[t]{2}{*}{ Verão } & $\mathrm{P}_{1}$ & $7,35 \pm 0,05$ & $25,17 \pm 0,76$ & $55,67 \pm 1,15$ & $1,87 \pm 0,23$ & $8,14 \pm 0,86$ \\
\hline & $\mathrm{P}_{2}$ & $7,51 \pm 0,01$ & $25,17 \pm 1,04$ & $56,17 \pm 0,76$ & $1,80 \pm 0,17$ & $7,83 \pm 0,67$ \\
\hline \multirow[t]{2}{*}{ Outono } & $\mathrm{P}_{1}$ & $7,30 \pm 0,28$ & $24,00 \pm 1,00$ & $51,18 \pm 5,66$ & $1,23 \pm 0,58$ & $9,33 \pm 0,51$ \\
\hline & $\mathrm{P}_{2}$ & $7,39 \pm 0,21$ & $24,17 \pm 1,26$ & $52,93 \pm 6,26$ & $1,35 \pm 0,66$ & $9,40 \pm 0,26$ \\
\hline \multirow[t]{2}{*}{ Inverno } & $\mathrm{P}_{1}$ & $7,33 \pm 0,10$ & $23,17 \pm 1,04$ & $54,83 \pm 0,81$ & $2,20 \pm 0,36$ & $8,34 \pm 0,51$ \\
\hline & $\mathrm{P}_{2}$ & $7,65 \pm 0,27$ & $23,33 \pm 1,15$ & $54,33 \pm 0,95$ & $2,33 \pm 0,29$ & $8,72 \pm 0,48$ \\
\hline Média \pm sd & & $7,53 \pm 0,47$ & $24,40 \pm 3,21$ & $54,90 \pm 1,18$ & $1,84 \pm 0,31$ & $8,41 \pm 0,89$ \\
\hline
\end{tabular}


Tabela 2. Concentração dos macronutrientes $\left(\mathrm{g} \mathrm{kg}^{-1}\right)$ do mexilhão dourado de dois pontos de coleta $\left(\mathrm{P}_{1}=\right.$ tanque rede e $\mathrm{P}_{2}=$ boia localizada a $100 \mathrm{~m}$ do tanque rede) na área aquícola do reservatório da usina hidrelétrica de Itaipu Binacional. $(\mathrm{n}=12)$

\begin{tabular}{|c|c|c|c|c|c|c|c|}
\hline \multirow[t]{2}{*}{ Analito } & \multicolumn{3}{|c|}{$\mathrm{P}_{1}$} & \multicolumn{3}{|c|}{$\mathrm{P}_{2}$} & \multirow[t]{2}{*}{$\mathrm{CV} \%$} \\
\hline & Mínimo & Média & Máximo & Mínimo & Média & Máximo & \\
\hline $\mathrm{N}$ & 21,88 & 26,54 & 32,38 & 14,00 & 25,08 & 35,00 & 19,39 \\
\hline $\mathrm{P}$ & 1,08 & 1,66 & 2,17 & 1,12 & 1,59 & 2,02 & 20,18 \\
\hline K & ND & 0,57 & 2,70 & ND & 0,33 & 1,05 & 140,10 \\
\hline $\mathrm{Mg}$ & 0,50 & 5,67 & 13,65 & 0,06 & 4,74 & 12,25 & 91,90 \\
\hline $\mathrm{Ca}$ & 66,30 & 110,54 & 148,75 & 89,05 & 113,24 & 141,05 & 22,91 \\
\hline
\end{tabular}

p > 0,05; CV = Coeficiente de variação; $\mathrm{ND}=$ não detectado pelo método de espectrometria de absorção atômica, modalidade chama (LQ 0,01 $\mathrm{g}$ kg $\left.{ }^{-1}\right)$

Tabela 3. Concentrações $\left(\mathrm{mg} \mathrm{kg}^{-1}\right)$ de micronutrientes e metais tóxicos do mexilhão dourado coletado em dois pontos $\left(\mathrm{P}_{1}=\right.$ tanque rede e $\mathrm{P}_{2}=$ boia localizada a $100 \mathrm{~m}$ do tanque rede) na área aquícola do reservatório da usina hidrelétrica de Itaipu Binacional, durante o período de abril de 2009 a março de 2010 e limites permitidos pela legislação brasileira em vigor (Brasil, 1965)

\begin{tabular}{|c|c|c|c|c|c|c|c|c|}
\hline \multirow{2}{*}{ Analito } & \multicolumn{3}{|c|}{$\mathrm{P}_{1}$} & \multicolumn{3}{|c|}{$\mathrm{P}_{2}$} & \multirow{2}{*}{$\mathrm{CV} \%$} & \multirow{2}{*}{ Brasil (1965) } \\
\hline & Mínimo & Média & Máximo & Mínimo & Média & Máximo & & \\
\hline $\mathrm{Cu}$ & 2,00 & 13,58 & 27,00 & 3,00 & 13,16 & 30,00 & 75,52 & 30,00 \\
\hline $\mathrm{Fe}$ & 745,00 & 1268 & 1688 & 640,00 & 1290,20 & 1734 & 29,15 & $\mathrm{NC}$ \\
\hline $\mathrm{Mn}$ & 42 & 181,83 & 336,00 & 50,00 & 153,00 & 422,00 & 72,24 & $\mathrm{NC}$ \\
\hline $\mathrm{Zn}$ & 4 & 22,91 & 48,00 & 6,00 & 23,58 & 45,00 & 74,37 & 50,00 \\
\hline $\mathrm{Cd}$ & ND & 3,33 & 7,00 & ND & 3,08 & 7,00 & 104,98 & 1,00 \\
\hline $\mathrm{Pb}$ & 16 & 35,25 & 60,00 & 12,00 & 32,58 & 51,00 & 53,37 & 2,00 \\
\hline $\mathrm{Cr}$ & ND & 4,08 & 6,00 & 2,00 & 4,83 & 7,00 & 39,02 & 0,10 \\
\hline $\mathrm{MPI}_{1}$ & 17,92 & 29,98 & 39,45 & 20,18 & 34,36 & 55,39 & 32,27 & $\mathrm{NC}$ \\
\hline $\mathrm{MPI}_{2}$ & 6,93 & 10,83 & 16,00 & 5,29 & 9,92 & 11,83 & 22,62 & $\mathrm{NC}$ \\
\hline
\end{tabular}

$\mathrm{CV}=$ Coeficiente de variação; $\mathrm{ND}=$ não detectado pelo método de espectrometria de absorção atômica, modalidade chama $\left(\mathrm{LQ} 0,01 \mathrm{mg} \mathrm{kg}^{-1}\right) ; \mathrm{NC}=$ não constam valores máximos permitidos nesta legislação; $\mathrm{MPI}_{1}=$ Índice de poluição por metais pesados; $\mathrm{MPI}_{2}=$ Índice de poluição por metais tóxicos.

superior à recomendada pela legislação brasileira, em bilvalves marinhos (Anomalocardia brasiliana, Brachidontes exustus, Iphigenia brasiliana, Crassostrea sp.). Corroborando os resultados do presente trabalho, estudos ${ }^{22}$ com ostra de mangue (Crassostrea brasiliana) quantificaram índices de $\mathrm{Cu}\left(2,8 \mathrm{mg} \mathrm{kg}^{-1}\right)$ e $\mathrm{Zn}\left(4,02 \mathrm{mg} \mathrm{kg}^{-1}\right)$ abaixo dos limites sugeridos pela ANVISA. ${ }^{20}$

Estudando a contaminação ambiental por metais pesados por meio do mexilhão Perna perna, na Ilha de Santana-SE, os autores ${ }^{23}$ encontraram valores de 5,10; 567,00 e 8,20 $\mathrm{mg} \mathrm{kg}^{-1}$, respectivamente, para $\mathrm{Cu}, \mathrm{Fe}$ e $\mathrm{Mn}$, inferiores aos detectados no mexilhão dourado estudado em ambiente continental no reservatório da usina hidroelétrica da Itaipu Binacional (Tabela 3).

As concentrações de $\mathrm{Cd}, \mathrm{Pb}$ e $\mathrm{Cr}$ encontradas nos mexilhões não diferem $(p>0,05)$ nos dois pontos do cultivo de peixes em tanques rede (Tabela 3 ), sendo que os valores se encontram em uma quantidade muito superior àquela estipulada pela ANVISA, ${ }^{20}$ que é de 1,$0 ; 2,0 \mathrm{e}$ $0,1 \mathrm{mg} \mathrm{kg}^{-1}$, respectivamente, podendo ser prejudicial à cadeia alimentar, pois níveis elevados destes metais pesados causam a contaminação do meio hídrico e, consequentemente, a intoxicação das espécies neste habitat, podendo, indiretamente, atingir o ser humano por meio da translocação dos metais entre os diferentes níveis tróficos. ${ }^{1}$ Porém, a toxidez é pertinente à presença destes metais no ambiente, visto que, tanto elementos essenciais (sódio, potássio, cálcio, ferro, zinco, cobre, níquel e magnésio) como não essenciais (arsênio, chumbo, cádmio, cromo, mercúrio, alumínio, titânio, estanho e tungstênio) são tóxicos aos organismos vivos, quando presentes em altas concentrações. ${ }^{21}$ Metais como cádmio, por exemplo, não são essenciais e podem se tornar altamente tóxicos mesmo em baixas concentrações, ${ }^{23}$ pois bioacumulam por muitos anos para posteriormente serem apresentados os primeiros sintomas de intoxicação. ${ }^{24}$

Os resultados das concentrações de macronutrientes e metais pesados, considerando as estações do ano, encontram-se na Tabela 4.
A quantificação das concentrações de Ca e Mg na primavera e verão foram inferiores $(\mathrm{p}<0,05)$ às observadas no outono e inverno. Verificou-se que os valores de N, K, Cr e MPI não diferiram sazonalmente ( $\mathrm{p}>0,05)$. As concentrações dos metais pesados $\mathrm{Cu}, \mathrm{Fe}, \mathrm{Mn}$, $\mathrm{Zn}, \mathrm{Cd}$ e $\mathrm{Pb}$, tanto na primavera quanto no verão, foram superiores $(\mathrm{p}<0,01)$ ao outono e inverno, diferindo dos resultados apresentados por outros autore ${ }^{25}$ que, ao descreverem as concentrações de $\mathrm{Cd}, \mathrm{Cr}$, $\mathrm{Cu}, \mathrm{Fe}, \mathrm{Mn}, \mathrm{Ni}, \mathrm{Pb}$ e Zn em Perna perna de três praias na costa Norte do estado do Rio de Janeiro, não encontraram tendência sazonal de acumulação. Os metais $\mathrm{Cd}, \mathrm{Pb}$ e $\mathrm{Cr}$, independente da estação do ano ou do ponto de coleta do mexilhão na área aquícola, encontram-se em uma concentração muito superior àquela estipulada pela ANVISA. ${ }^{20}$

No presente trabalho não foi detectado Cd no outono e inverno, porém isso não significa que este não esteja presente no mexilhão dourado, podendo estar em concentrações inferiores ao limite de quantificação (LQ $0,01 \mathrm{mg} \mathrm{kg}^{-1}$ ) pela metodologia de espectrometria de absorção atômica com chama (F AAS). A metodologia de espectrometria de absorção atômica modalidade forno de grafite (GF AAS) poderia ser empregada para comprovar estes resultados devido a sua maior sensibilidade, porém o Laboratório de Química Ambiental e Instrumental da Unioeste não possui esta atomização. A quantidade de $\mathrm{Cd}$ variou de 6,33 a $6,50 \mathrm{mg} \mathrm{kg}^{-1}$, respectivamente, na primavera e verão (Tabela 4). Concentrações de Cd acima dos valores máximos permitidos pela legislação brasileira em vigor ${ }^{20}$ também foram encontrados em moluscos bivalves, porém de água salgada. ${ }^{26}$ Resultados inferiores aos do presente trabalho para $\mathrm{Cd}$ $\left(0,11 \mathrm{mg} \mathrm{kg}^{-1}\right)$ foram encontrados por Machado et al. ${ }^{27} \mathrm{em}$ ostra de mangue (Crassostrea brasiliana) e valores para $\mathrm{Pb}, \mathrm{Cr}$ e $\mathrm{Cd}$ relacionados ao mexilhão Perna perna, que correspondem a 0,38; 1,25 e $1,80 \mathrm{mg} \mathrm{kg}^{-1}$, respectivamente. ${ }^{28}$

Considerando que as comparações entre os níveis de contaminação foram realizadas por meio dos valores máximos de tolerância 
Tabela 4. Valores médios e desvio padrão de macronutrientes, metais pesados e índice de poluição por metal (MPI ${ }_{1}$ ) do mexilhão dourado, nas quatro estações do ano, independente do ponto de coleta, e precipitação $(\mathrm{mm})$ na área aquícola do reservatório da usina hidrelétrica de Itaipu Binacional, durante o período de abril de 2009 a março de 2010

\begin{tabular}{|c|c|c|c|c|}
\hline & Primavera & Verão & Outono & Inverno \\
\hline \multicolumn{5}{|c|}{ Macronutriente $\left(\mathrm{g} \mathrm{kg}^{-1}\right)$} \\
\hline $\mathrm{N}$ & $25,53 \pm 8,24 \mathrm{a}$ & $28,73 \pm 3,25 \mathrm{a}$ & $23,40 \pm 1,76 \mathrm{a}$ & $25,59 \pm 3,81 \mathrm{a}$ \\
\hline $\mathrm{P}$ & $1,84 \pm 0,23$ a & $1,82 \pm 0,30 \mathrm{a}$ & $1,31 \pm 0,14 \mathrm{~b}$ & $1,53 \pm 0,17 \mathrm{ab}$ \\
\hline $\mathrm{K}$ & $0,43 \pm 0,78$ a & $0,77 \pm 1,00 \mathrm{a}$ & $0,24 \pm 0,08 \mathrm{a}$ & $0,35 \pm 0,14 \mathrm{a}$ \\
\hline $\mathrm{Mg}$ & $0,88 \pm 0,74 \mathrm{~b}$ & $0,87 \pm 0,61 \mathrm{~b}$ & $7,58 \pm 1,65$ a & $10,38 \pm 1,62 \mathrm{a}$ \\
\hline $\mathrm{Ca}$ & $86,21 \pm 9,81 \mathrm{~b}$ & $90,73 \pm 1,09 \mathrm{~b}$ & $139,30 \pm 9,12 \mathrm{a}$ & $131,30 \pm 2,63 \mathrm{a}$ \\
\hline \multicolumn{5}{|c|}{ Metal pesado $\left(\mathrm{mg} \mathrm{kg}^{-1}\right)$} \\
\hline $\mathrm{Cu}$ & $23,00 \pm 4,23 \mathrm{a}$ & $22,33 \pm 3,56 a$ & $3,83 \pm 1,33 \mathrm{~b}$ & $4,33 \pm 1,03 \mathrm{~b}$ \\
\hline $\mathrm{Fe}$ & $1639,17 \pm 65,88$ a & $1583,33 \pm 140,23$ a & $973,00 \pm 199,60 \mathrm{~b}$ & $920,83 \pm 124,39 \mathrm{~b}$ \\
\hline $\mathrm{Mn}$ & $275,00 \pm 103,65 \mathrm{a}$ & $254,33 \pm 84,71 \mathrm{a}$ & $88,00 \pm 31,70 \mathrm{~b}$ & $52,33 \pm 5,68 \mathrm{~b}$ \\
\hline $\mathrm{Zn}$ & $39,66 \pm 2,88$ a & $39,16 \pm 6,74 \mathrm{a}$ & $6,83 \pm 2,14 \mathrm{~b}$ & $7,33 \pm 1,75 b$ \\
\hline $\mathrm{Cd}$ & $6,50 \pm 0,55 \mathrm{a}$ & $6,33 \pm 0,52 \mathrm{a}$ & ND & ND \\
\hline $\mathrm{Pb}$ & $51,83 \pm 2,93 \mathrm{a}$ & $50,16 \pm 4,12 \mathrm{a}$ & $17,83 \pm 3,66 b$ & $15,83 \pm 2,56 b$ \\
\hline $\mathrm{Cr}$ & $4,66 \pm 1,03$ a & $4,16 \pm 1,17$ a & $5,00 \pm 1,67$ a & $4,00 \pm 2,83 \mathrm{a}$ \\
\hline $\mathrm{MPI}_{1}$ & $13,46 \pm 1,63 \mathrm{a}$ & $12,56 \pm 2,07 \mathrm{a}$ & $9,31 \pm 2,05$ a & $9,73 \pm 3,75$ a \\
\hline PPT & $244,00 \pm 74,83 \mathrm{a}$ & $177,60 \pm 48,40 \mathrm{a}$ & $94,60 \pm 36,0 \mathrm{~b}$ & $107,10 \pm 52,28 \mathrm{~b}$ \\
\hline
\end{tabular}

Letras iguais em cada linha não diferem entre si ( $\mathrm{p}>0,01) ; \mathrm{ND}=$ não detectado pelo método de espectrometria de absorção atômica, modalidade chama (LQ $\left.0,01 \mathrm{mg} \mathrm{kg}^{-1}\right)$. *PPT = precipitação, dados do Instituto Tecnológico Simepar/Santa Helena-PR.

estipulados na legislação para alimentos, cabe ressaltar que o mexilhão Limnoperna fortunei não é fonte direta de alimento para o homem. Porém, estes moluscos são extremamente importantes na cadeia alimentar de muitas espécies de peixes, sendo consumidos nos diferentes níveis tróficos da dieta de peixes como o pintado, jundiá e o armado, espécies representativas da pesca comercial da Bacia do Paraná III. Portanto, as alterações nas concentrações dos metais podem se tornar altamente tóxicas considerando-se os processos de bioacumulação e biomagnificiência. Além disto, os metais contaminantes podem ser difundidos pela cadeia trófica local e também dispersos espacialmente, uma vez que os peixes migram por extensões consideráveis para reprodução e alimentação, entre outros comportamentos fisiológicos.

Alguns estudos têm relatado que a estação do ano pode desempenhar um papel na acumulação de metais nos tecidos dos organismos aquáticos. ${ }^{29,30} \mathrm{~A}$ principal razão da ocorrência de alterações nas concentrações de metais em peixes por mudanças sazonais é resultante de modificações de fatores intrínsecos. A existência da variação temporal com menores e maiores densidades da larva de mexilhão dourado, respectivamente, no período mais frio do ano (julho/agosto) e na primavera (setembro/outubro) nos Rios Paraná e Iguaçu na região de Foz do Iguaçu-PR,$^{31}$ alterando a fonte disponível de alimentos para os predadores destes moluscos pode ser considerada como um dos exemplos.

Apenas para os valores médios de $\mathrm{Mg}$ e $\mathrm{MPI}_{1}$ houve interação entre o local de coleta e a estação do ano. A concentração de $\mathrm{Mg}$ não diferenciou ( $p>0,05)$ entre os locais no inverno, primavera e verão, porém no outono houve uma maior quantidade $(\mathrm{p}<0,01)$ de $\mathrm{Mg}$ $\left(11,55 \mathrm{mg} \mathrm{kg}^{-1}\right)$ no mexilhão em relação aos dois locais de coleta. Independente do local de coleta, os valores médios de $\mathrm{Mg}$ do mexilhão dourado no inverno e outono foram superiores $(\mathrm{p}<0,01)$ aos encontrados na primavera e verão. $\mathrm{O} \mathrm{MPI}_{1}$ dos mexilhões coletados incrustados no tanque rede $\left(\mathrm{P}_{1}\right)$ não foi influenciado $(\mathrm{p}>0,05)$ pela estação do ano. Porém, para os mexilhões coletados na boia náutica $\left(\mathrm{P}_{2}\right)$, a $100 \mathrm{~m}$ do tanque rede, na primavera e verão os índices de metal pesado foram superiores $(\mathrm{p}<0,01)$ aos do inverno e outono e aos coletados no tanque rede.

O mexilhão é uma espécie epifaunal e possui bisso para fixação nos tanques rede $\left(\mathrm{P}_{1}\right)$ e na boia náutica $\left(\mathrm{P}_{2}\right)$, permanecendo o restante de sua longevidade de aproximadamente 3 anos. ${ }^{10}$ Tais características biológicas deste bivalvo associadas às características hidrológicas do reservatório de Itaipu Binacional podem contribuir para os efeitos sazonais da bioacumulação ou, provavelmente, da capacidade de depuração dos moluscos durante as alterações no regime hídrico do local estudado.

Pode-se verificar que na primavera e verão houve uma maior bioacumulação de metais, possivelmente relacionada com a menor capacidade de drenagem antes da primavera, caracterizada pelos baixos índices pluviométricos durante estas estações do ano e um provável incremento das fontes poluidoras e dos efeitos dos efluentes impactantes deslocados após o período de maior concentração das chuvas durante o período de estudo (Figura 1).

O aumento dos níveis de poluição dos recursos aquáticos tem um efeito negativo sobre a produtividade aquícola, segurança dos produtos e rentabilidade. A poluição pode estar relacionada ao aumento da concentração de elementos químicos oriundos dos esgotos domésticos, lixo e escoamento de resíduos agrícolas e pecuários, levando às alterações no índice de qualidade de água, ${ }^{32}$ eutrofização e, possivelmente, à bioacumulação de metais pesados, entre outros.

A utilização do mexilhão dourado como bioindicador pode servir de ferramenta para quantificar a possível influência do sistema intensivo de peixes em tanques rede na área aquícola estudada. A avaliação da bioacumulação e o monitoramento da qualidade das águas, dos peixes e das rações comerciais são fundamentais para um controle rigoroso sobre os nutrientes e as substâncias encontradas, cujas concentrações indicam o grau da poluição ou contaminação, podendo ocasionar efeitos acumulativos sobre a fauna existente.

A usina hidrelétrica da Itaipu Binacional, localizada na região Oeste do Paraná, possui o $7^{\circ}$ maior reservatório do Brasil, com uma área inundada de $1.350 \mathrm{~km}^{2}$ e o melhor índice de aproveitamento da água para produzir energia, além de seus atrativos turísticos como, praias artificiais, pesca esportiva e comercial e uma importante área destinada aos parques aquícolas. ${ }^{33}$ Porém, os impactos econômicos e ecológico da invasão do mexilhão podem ameaçar o potencial do reservatório de Itaipu Binacional, caso não seja adotadas medidas de controle que regulem a distribuição e a persistência de espécies invasoras como L. fortunei. 
(a)

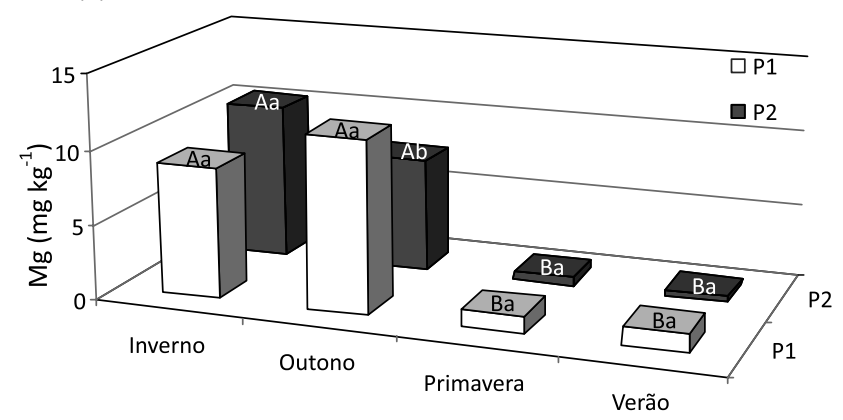

(b)

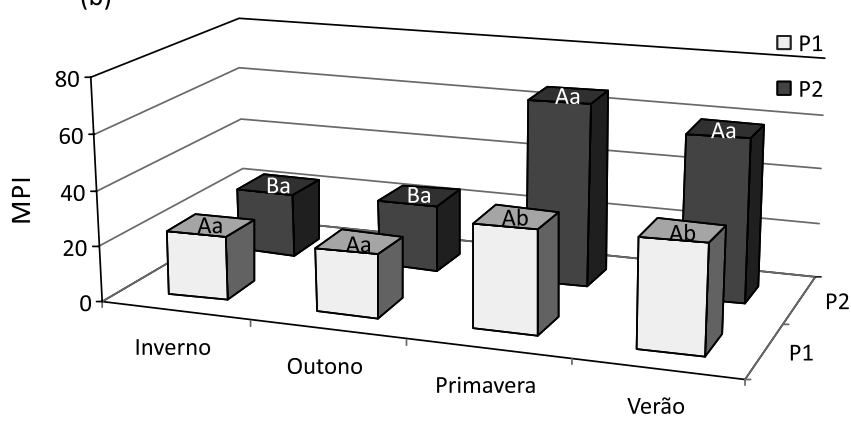

Figura 1. (a) Valores médios de magnésio $(\mathrm{Mg})$; (b) índice de poluição por metal (MPI) do mexilhão dourado para os pontos de coleta $\left(P_{1}\right.$ e $\left.P_{2}\right)$, referente às estações do ano na área aquícola do reservatório da usina hidrelétrica de Itaipu Binacional. Médias seguidas de diferentes letras maiúsculas entre as estações e letras minúsculas entre os pontos diferem pelo teste de Tukey $(p<0,05)$

\section{CONCLUSÕES}

O mexilhão dourado (Limnoperna fortunei) pode ser utilizado como bioindicador de metais pesados, pois foram encontrados níveis elevados de $\mathrm{Cd}, \mathrm{Pb}$ e $\mathrm{Cr}$ pois, além de serem tóxicos, há um expressivo potencial poluente nos sedimentos, nas plantas e animais, bioacumulando-se ao longo da cadeia trófica. O equilíbrio da biota aquática poderá ser alterado, por meio da contaminação ambiental e dos distúrbios decorrentes da superexposição e dispersão especial, necessitando de controle da espécie invasora.

As deposições de $\mathrm{N}, \mathrm{K}$ e Cr no mexilhão não sofreram efeito sazonal.

O ponto de coleta do mexilhão não influenciou nas concentrações de nutrientes e metais pesados.

Todas as amostras $(n=24)$ do bioindicador utilizado estavam contaminadas com os elementos traços $\mathrm{Pb}$ e $\mathrm{Cr}$ em proporções superiores aos preconizados pela legislação, indicando também a superexposição da biota e contaminação ambiental da área aquícola na época estudada.

\section{AGRADECIMENTOS}

Ao Laboratório de Química Ambiental e Instrumental da Unioeste, ao Grupo de Estudos em Solos e Meio Ambiente (Gesoma) e ao Prof. Dr. C. Y. Tsutsumi, Unioeste.

\section{REFERÊNCIAS}

1. Agustini, M. A. B.; Mucelin, C. A.; Resumos do $6^{\circ}$ Encontro Nacional de Difusão Tecnológica, Medianeira, Brasil, 2009.
2. Pérez, E.; Blasco, J.; Solé, M.; Mar. Environ. Res. 2004, 58, 275.

3. Darrigran, G. A.; Damborenea, M. C.; Am. Malacol. Bull. 2005, 20, 105.

4. Giordani, S.; Neves, P. S.; Andreoli, C. V.; Resumos do $23^{\circ}$ Congresso Brasileiro de Engenharia Sanitária e Ambiental, Campo Grande, Brasil, 2005.

5. http://www.cpap.embrapa.br/publicacoes, acessada em Dezembro 2012.

6. Santos, C. P.; Würdig, N. L.; Mansur, M. C. D.; Rev. Bras. Zool. 2005, 22,702 .

7. Lei, J.; Payne, B. S.; Wang, S. Y.; Can. J. Fish. Aquat. Sci. 1996, 53, 29.

8. Filippo, R.; Mexilhão Dourado nos Ecossistemas Brasileiros, SEPRONEWS, Série meio ambiente, 2003, Ano 1, número 3.

9. Wang, Y.; Liang, L.; Shi, J.; Jiang, G.; Environ. Int. 2005, 31, 1103.

10. Maroñas, M. E.; Darrigran, G. A.; Sendra, E. D.; Breckon, G.; Hydrobiologia 2003, 495, 41.

11. AOAC; Official Methods of Analysis, $18^{\text {th }}$ ed., Association of Official Analytical Chemists: Gaithersburg, 2005.

12. Welz, B.; Sperling, M.; Atomic Absorption Spectrometry, $2^{\text {nd }}$ ed., WileyVCH: Weinheim, 1999.

13. Tedesco, M. J.; Gianello, C.; Bissani, C. A.; Bohnen, H.; Volkweiss, S. J.; Análises de Solo, Plantas e Outros Materiais, $2^{\mathrm{a}}$ ed., Universidade Federal do Rio Grande do Sul: Porto Alegre, 1995 (Boletim técnico, 5).

14. Usero, J.; Gonzalez-Regalado. E.; Gracia, I.; Mar. Pollut. Bull. 1996, 32, 305.

15. SAS - Statistical Analysis System; Software: Guia do usuário, versão 8.0. Cary, EUA, 1999.

16. http://www.mpa.gov.br/port/conama/res/res35705.pdf, acessada em Dezembro 2012.

17. Bueno, G. W.; Marengoni, N. G.; Gonçalves Júnior, A. C.; Boscolo, W. R.; Teixeira, R. A.; Acta Sci. Biol. Sci. 2008, 30, 237.

18. Silva, D.; Dissertação de Mestrado, Universidade Federal de Santa Catarina, Brasil, 2007.

19. Agripino, A. A.; Dissertação de Mestrado, Universidade Nova de Lisboa, Portugal, 2009.

20. Brasil, Leis, Decretos, etc; Decreto ${ }^{\circ} 55871$, de 26/3/1965. Modifica o decreto $\mathrm{n}^{\circ}$ 50040, de 24/1/1961 referente a normas regulamentadoras do emprego de aditivos para alimentos, alterado pelo Decreto $n^{\circ} 691$, de 13/3/1962, Diário Oficial, Brasília, DF, 1965, seç. 1, pt. 1, p. 3611.

21. Mokhtar, M. B.; Aris, A. Z.; Munusamy, V.; Praveena, S. M.; Eur. J. Sci. Res. 2009, 30, 348.

22. Porto, L. C. S.; Ethur, E. M.; Cienc. Rural 2009, 39, 2512.

23. Viarengo, A.; Mar. Pollut. Bull. 1985, 16, 158.

24. http://www.astdr.cdc.gov/cercla/07list.html, acessada em Dezembro 2012.

25. Ferreira, A. G.; Machado, A. L. S.; Zalmon, I. R.; Braz. Arch. Biol. Terchnol. 2004, 47, 319.

26. Teixeira, R. R.; Simões, R. C.; Brandão, J. M.; Matos, W. N.; Freitas, V. M. S.; Fernandes, L. G.; Resumos do $8^{\circ}$ do Congresso de Ecologia do Brasil, Caxambu, Brasil, 2007.

27. Machado, I. C.; Maio, F. D.; Kira, C. S.; Carvalho, M. F. V.; Rev. Inst. Adolfo Lutz, 2002, 61, 13.

28. Carvalho, C. E. V.; Cavalcante, M. P. O.; Gomes, M. P.; Faria, V. V.; Rezende, C. E.; Ecotoxicol. Environ. Rest. 2001, 4, 1.

29. Kargin, F.; Water, Air, Soil Pollut. 1996, 90, 557.

30. Chambo, A. P. S.; Dissertação de Mestrado, Universidade Estadual do Oeste do Paraná, Brasil, 2012.

31. Pestana, D.; Pie, M. R.; Ostrensky, A.; Boeger, W. A.; Andreoli, C.; Franceschi, F.; Lagos, P.; Braz. Arch. Biol. Technol. 2008, 51, 607.

32. Carvalho, A. R.; Schlittler, F. H. M.; Tornisielo, V. L.; Quim. Nova 2000, $23,618$.

33. http://www.itaipubinacional.gov.br, acessada em Dezembro 2012. 